\title{
Massive duodenal variceal bleed: endoscopic ultrasonography of ruptured varix and successful endoscopic clipping treatment
}

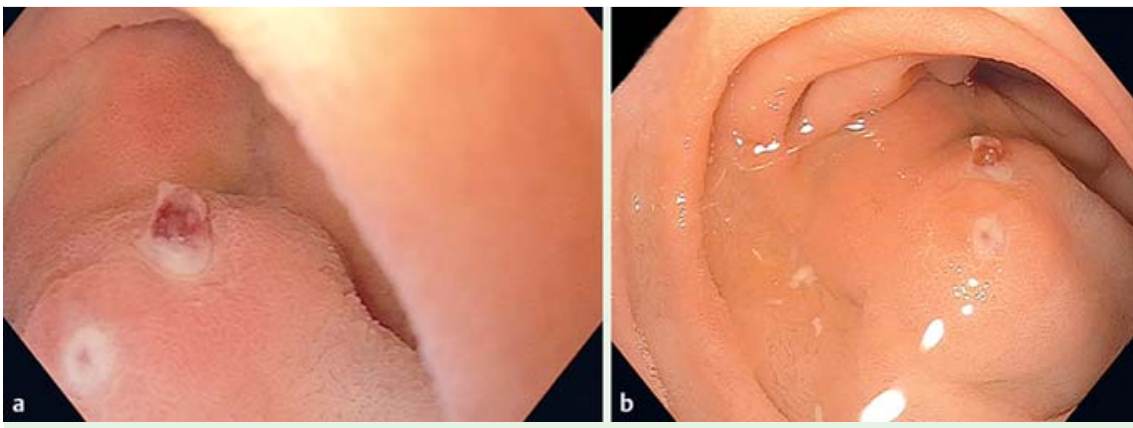

Fig. 1 Endoscopic view of the duodenal varix in a 50-year-old woman with severe gastrointestinal bleeding: $\mathbf{a}$ ulcerations with a blood clot on one. $\mathbf{b}$ another view of the ulceration with blood clot.
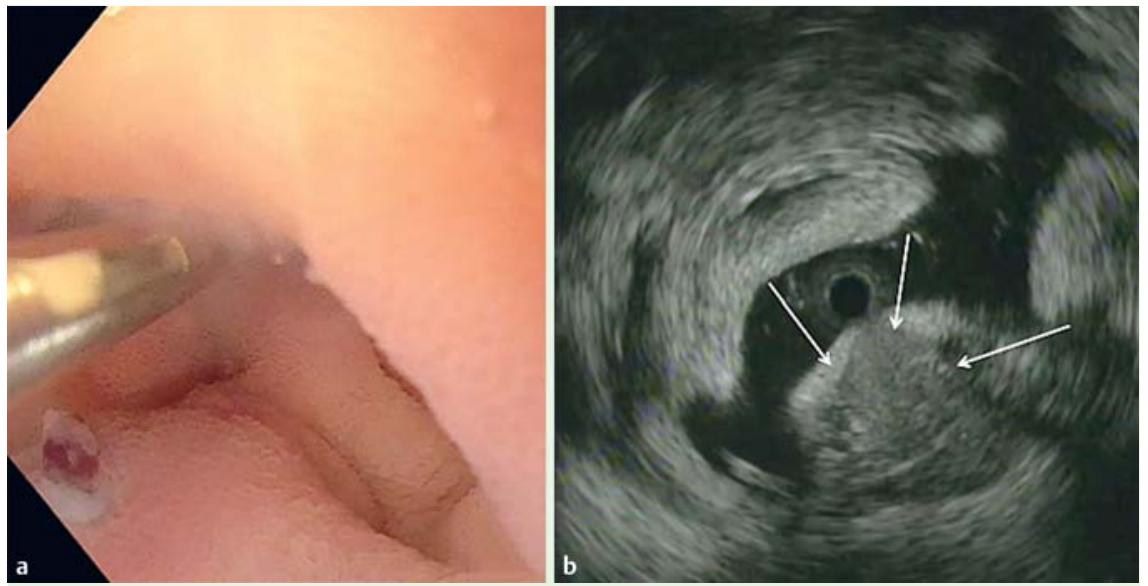

Fig. 2 Examination using endoscopic ultrasound (EUS): a EUS miniprobe over the varix; b EUS appearance of the blood flow in the varix (arrows).

Duodenal varices are a rare cause of upper gastrointestinal $(\mathrm{GI})$ bleeding $[1-5]$ and endoscopic management is not standardized $[1,2]$.

We report the case of a 50-year-old woman with alcoholic cirrhosis who was referred for severe digestive tract bleeding with hematemesis and hemodynamic instability. After medical management, emergency endoscopy (GIF 190, 2.8-mm operating channel; Olympus, Tokyo, Japan) showed a transverse varix in the second part of the duodenum, with two ulcerations one of which had a blood clot ( $\mathrm{Fig.1}$ a, $\odot$ Fig.1b). This finding was highly suggestive of a variceal rupture site. We immediately performed an endoscopic ultrasound (EUS) exploration (2.5-mm miniprobe, Olympus) to confirm and de- lineate the varix and its feeding vessel $(\bullet$ Fig. 2a, $\odot$ Fig. 2b). The varix was $8 \mathrm{~mm}$ large and connected at its anterior part (left) to a transmural perforating vein. A first clip (Instinct; Cook Medical, Bloomington, Indiana, USA) was deployed on the left part of the varix ( $\odot$ Fig.3a, $\odot$ Fig. 3 b) and was immediately effective in reducing the blood flow as shown by EUS ( $\bullet$ Fig. 3c, - Fig. $3 \mathrm{~d}$, O Fig. 3 e). A second clip was applied close to the first one to grasp a larger piece of tissue. We achieved hemostasis by placing two additional hemoclips on the posterior (right) part of the varix and then two on the bleeding point ( $\bullet$ Fig.4a). We confirmed the disappearance of the vessel by a third EUS miniprobe examination ( $\bullet$ Fig. $4 \mathbf{b}$ ). Clinical outcomes were positive for the patient

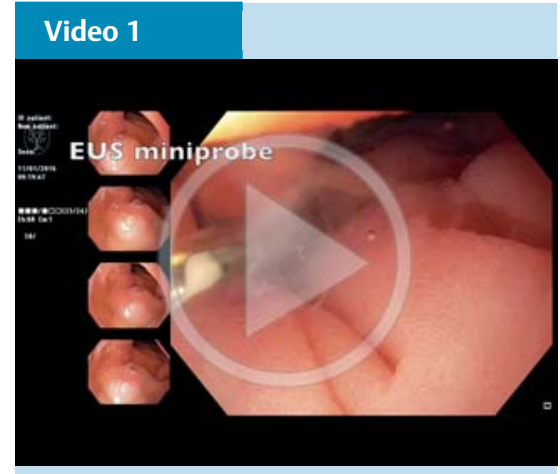

Endoscopic ultrasound (EUS)-aided confirmation and clipping for a ruptured duodenal varix.

with no bleeding recurrence in the following days.

To summarize, in rare cases duodenal varices are responsible for GI bleeding. Previous reports describe treatment of such varices with sclerotherapy [5], glue injection, or with a transhepatic portosystemic shunt (TIPS) combined with clipping [4]. However we have previously encountered lung embolization during treatment of duodenal varices by glue injection, and duodenal necrosis as a result of band ligation since the entire duodenal wall can be suctioned into the band. Thus, we usually use clipping for duodenal varices as it is precise and safe. Use of the EUS miniprobe allows assessment of the effectiveness of the hemostatic treatment by showing the vessel's disappearance or reduction in size.

\section{Endoscopy_UCTN_Code_TTT_1AO_2AD}

\section{Competing interests: None}

\section{Isabelle Lienhart ${ }^{1}$, Adriane Lesne ${ }^{1}$, Eduardo Couchonnal ${ }^{1}$, Jérôme Rivory ${ }^{1}$, Leonardo Sosa-Valencia ${ }^{1}$, Thierry Ponchon $^{1,2}$, Mathieu Pioche ${ }^{1,2}$}

${ }^{1}$ Gastroenterology and Endoscopy Unit, Pavillon L, Edouard Herriot Hospital, Lyon, France

2 Inserm U1032, Labtau, Lyon, France 


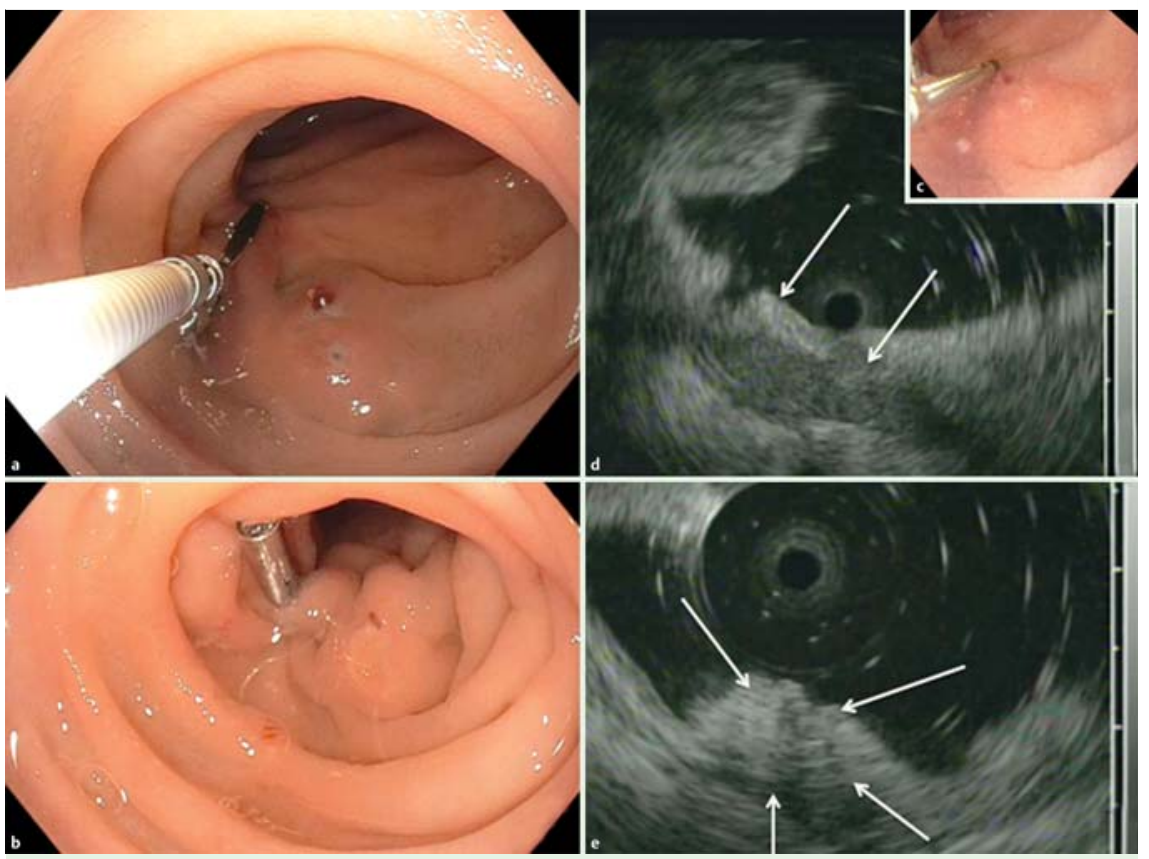

Fig. 3 Endoscopic treatment by clipping, and immediate result: a deployment of first clip; $\mathbf{b}$ first clip in place; c endoscopic ultrasound (EUS) miniprobe position; d, e EUS images show decreased flow (arrows) in the residual vessel.
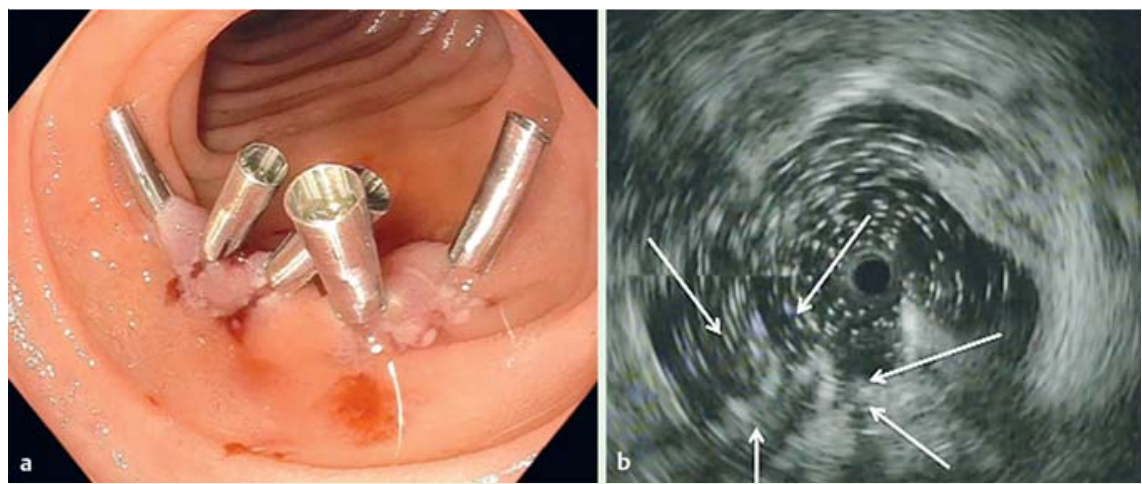

Fig. 4 Appearances after clipping: a endoscopic view just before the sixth clip was placed; b EUS image showing that blood flow in the vessel has been interrupted (arrows).

\section{References}

1 Rana SS, Bhasin DK, Sharma V et al. Clinical, endoscopic and endoscopic ultrasound features of duodenal varices: A report of 10 cases. Endosc Ultrasound 2014; 3: 54-57

2 Saad WE, Lippert A, Schwaner $S$ et al. Management of bleeding duodenal varices with combined TIPS decompression and transTIPS transvenous obliteration utilizing 3\% sodium tetradecyl sulfate foam sclerosis. J Clin Imaging Sci 2014; 4: 67

3 Steevens C, Abdalla M, Kothari TH et al. Massive duodenal variceal bleed; complication of extra hepatic portal hypertension: Endoscopic management and literature review. World J Gastrointest Pharmacol Ther 2015; 6: $248-252$

4 Taniguchi $H$, Shibagaki K et al. A case of ruptured duodenal varices successfully treated by combination therapy with endoscopic clipping and balloon-occluded retrograde transvenous obliteration. Nihon Shokakibyo Gakkai Zasshi Jpn J Gastro-Enterol 2015; 112: 1998 - 2004

5 Barbish AW, Ehrinpreis MN. Successful endoscopic injection sclerotherapy of a bleeding duodenal varix. Am J Gastroenterol 1993; 88: $90-92$

\section{Bibliography}

DOI http://dx.doi.org/

10.1055/s-0042-102959

Endoscopy 2016; 48: E80-E81

(c) Georg Thieme Verlag KG

Stuttgart · New York

ISSN 0013-726X

\section{Corresponding author}

\section{Mathieu Pioche, MD}

Endoscopy Unit, Digestive Disease Department H Pavillon, Edouard Herriot Hospital 69437 Lyon Cedex

France

Fax: +33-472-110147

mathieu.pioche@chu-lyon.fr 